\title{
The Complementarity Effect for Cdc25 Phosphatase Inhibitors
}

\author{
Wassila Soufi $^{1,2}$, Meriem Merad ${ }^{1,2}$, Faïza Boukli ${ }^{1,2}$, Saïd Ghalem ${ }^{1,2^{*}}$ \\ ${ }^{1}$ Department of Chemistry, Faculty of Sciences, Aboubakr Belkaid University, Tlemcen, Algeria \\ ${ }^{2}$ Laboratory of Naturals Products and Bio Actives, Tlemcen, Algeria \\ E-mail: s_ghalem2002@yahoo.fr \\ Received April 14, 2011; revised May 3, 2011; accepted May 30, 2011
}

\begin{abstract}
Cdc25 phosphatase have been regarded as attractive drug targets for anticancer therapies due to the correlation of their over expression with a wide variety of cancers. They are key regulators of cell cycle progression and play a central role in the checkpoint response to DNA damage. The role of Cdc25 s in cancer has become increasingly evident in recent years. More than 20 studies of patient samples are from diverse cancers show significant overexpression of Cdc25 with frequent correlation to clinical outcome. Recent screening and design efforts have yielded novel classes of inhibitors that show specificity for the Cdc25 s over other phosphatases and cause cell cycle arrest in vivo. Until now, quinone derivatives are among the most efficient inhibitors of Cdc25 phosphatase activity. Our research objective is to study the inhibition of the phosphathase Cdc25 through the molecular modeling methods.
\end{abstract}

Keywords: Cancer, Cdc25 Phosphatase, Molecular Modeling (MM, DM, and Docking), Naphtoquinone

\section{Introduction}

Cancer is a group of diseases characterized by uncontrolled cell division leading to the growth of abnormal tissue. These cells known as "malignant" different from the normal cells, present anomalies of structure and behavior. They will upset the architectural order of the normal cells while piling up and by pushing back these last before invading them. The knowledge of the cellular cycle makes it possible to consider the various means to fight against this anarchistic proliferation [1]. Cancers and leukemia are diseases which can touch the child as well as the adult and which are characterized by an abnormal and anarchistic proliferation of "normal" cells in the organism:

- Cells of blood and osseous marrow for leukemia, cells of the lymphoid bodies (spleen, ganglia...) for the lymphomas.

- Specific cells or not of a body for the solid tumors (of the brain, the bone, of kidney...).

At the beginning of the $20^{\text {th }}$ century, the objective of the researchers was to discover the agents that cause cancer. Thus much of heterogeneous factors can be at the origin of the development of tumors [2-5] which are the most known. Factors may be viral, chemical (benzene, aflatoxine), physical (ionizing radiations, ultraviolet light), traumatic, inflammatory, parasitic (tumors of the lip of the horse), skin cancer including burn scars [6] and nutritional ones [7,8].

Cdc25 phosphatases are dual specificity phosphatase. They play an essential role in cell cycle progression $[9,10]$, There are three types of Cdc25 phosphatases in man: Cdc25A, B and C. [11,12] they have a structure and a common catalytic mechanism. These proteins are composed of 300 to 600 amino acids and can be divided into two parts:

- The C-terminus represents about one third of the enzyme and contains the catalytic site. The latter has a pattern common to all CX5R protéine tyrosines phosphatases where $\mathrm{C}$ is a cysteine catalytic $\mathrm{X}$ and $\mathrm{R}$ different amino acids arginine

- He N-terminus acts as a regulator. This is the part that differs most between different sub-classs of Cdc25. It contains many phosphorylation sites [13,14].

The catalytic mechanism of dephosphorylation by Cdc25 is similar to that of PTP1B [15]. After nucleophilic attack by cysteine followed by protonation, there is departure from the substrate and formation of an intermediate phosphate. Hydrolysis frees the phosphate phosphatase and return (Figure 1). 


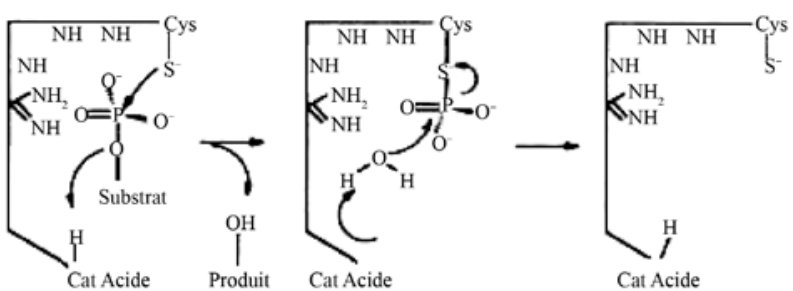

Figure 1. catalytic mechanism of dephosphorylation Phosphatase Cdc25 regulate cell division by acting on each individual cdk complexes (cyclin-dependent kinases).

Cdc25 phosphatases play a significant role in the regulation of the progression of eukaryotic cell cycle by activating cyclin Cdk that serve as central regulators of cell cycle with the lead role of each state of cell division. Due to a major contribution to cell cycle phosphatase Cdc25 have been implicated in oncogenic transformation and human cancers. Cdc25 phosphatases are present in a series of tumor cells including those from breast [16], colon [17,18], prostate [19] and lung [20,21]. Human Cdc25A and Cdc25B are defined as having oncogenic properties [22]. Recent studies have also shown the involvement of Cdc25A in the adhesion proliferation of acute myeloid leukemia (AML) cells [23]. Further evidence for the oncogenic property of Cdc25 phosphatases was provided by the pharmacological studies in which the treatment with the Cdc25 phosphatase inhibitors delayed the growth of the cancer cell lines expressing a high level of Cdc25 phosphatases [24]. It is likely that Cdc25A or Cdc25B leads to promotion of cell cycle progression in cancer cells, although it involved simultaneously in two counterparts which were also observed in more aggressive cancers [25]. Further to this section "Thus, inhibition of Cdc25 phosphatases may represent a novel therapeutic approach for the development of cancer therapy, although details about the involvement of Cdc25A and Cdc25B in the tumorigenesis remain to be clarified. Structural investigations of Cdc25 phosphatases have lagged behind the mechanistic and pharmacological studies. So far two X-ray crystal structures of the catalytic domains of Cdc25A and Cdc25B have been reported in their ligand-free forms only $[26,27]$ The lack of structural information about the nature of the interactions between Cdc25 phosphatases and small molecule inhibitors has made it a difficult task to discover good lead compounds for anticancer drugs. Nonetheless, a number of effective inhibitors Interest phosphatase Cdc25 Phosphatase Cdc25 heavily involved in the regulation of cell division could be potential oncogenes. Indeed, several studies have shown that phosphatases Cdc25A and B are over expressed in various kinds of cancers, which is not the case for Cdc25C [12]. Their over expression and their crucial role in cell cycle Cdc25A and B are the targets for the development of new anticancer [28-31].
There exist various types of treatment, they can be associated or used alone $[9,10]$. These treatments are:

\subsection{Chemotherapy}

It relies on the use of chemical agents that inhibit the reproduction and the rapid and uncontrolled growth of cancerous cells. We observe several anti- cancer chemical groups. These groups are based on the biochemical mechanism of action for their respective products or they will act either on the proteinic synthesis, or on the cellular division.

\subsection{Surgery}

Surgery is one of the oldest techniques of treatment of cancer. It involves excision of the tumor tissue presented. It alone can be sufficient treatment in some cases; it must involve either chemotherapy or radiotherapy.

\subsection{Radiotherapy}

It was implemented following the discovery of the 19th century of ionizing radiations by Roentgen, Pierre and Marie Curie [10]. Its purpose is to sterilize the loco-regional component of a tumor, not only in its part anatomically detectable but also its extensions little detectable.

\subsection{Inhibitors of Cdc25}

There are currently a number of inhibitors of Cdc25 structures varied. A large majority of them has a recurring motif quinone. The phosphatase Cdc25 is impliqued in the process of inflammation in the cancer disease.

Menadione (vitamin K3) was known for its antitumor activity and low toxicity compared with other anticancer agents derived quinones. That is why the team was interested in Ham's action on the phosphatase Cdc25. Their work shows that menadione inhibits irreversibly Cdc25 by forming a covalent bond with the active site of the enzyme. [32]. From these results, several teams have studied the activity of quinone derivatives on the phosphatase Cdc25.

Among thioalkyl derivatives, can be cited:

- Inhibitor_1 (Cpd 5), synthesized by the team of Tamura [33] is a partial competitive inhibitor of Cdc25 and irreversible

- Inhibitor_2 (NSC 95397): analogue Cpd 5, it is also an irreversible inhibitor with improved activity [34].

\subsection{Properties of Quinones}


The forms 1, 4-Naphthoquinone are yellow crystals and have a smell similar to benzoquinone. They can soluble in cold water, slightly soluble in oil ether and freely soluble in most polar organic solvents. In alkaline solutions it produces a reddish-brown color. Because of their aromatic stability, known as 1, 4-naphthoquinone derivatives have properties of anti-tumor and antibacterial effects. Naphthoquinone forms the core chemical structure of many natural compounds, most notably vitamin $\mathrm{K}$.

Many natural products have quinone-type structures; one of the most important of these is an anti-hemorrhagic: vitamin $\mathrm{K} 1$ that occurs in green plants and is a naphthoquinone-1, 4 substituted.

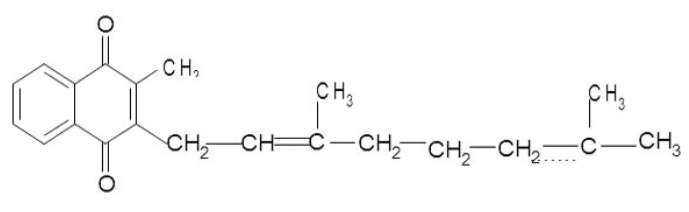

Vitamin K1

The structure of vitamin K1 was established by degradation and synthesis, it is surprising that the long side chain is not necessary for blood clotting because the methyl 1-2 naphthoquinone-1, 4 is almost as same in activity in vitamin $\mathrm{K}$ subtypes (Mole fraction equal to) [35].<smiles>CC1=CC(=O)c2ccccc2C1=O</smiles>

Méthy-2 naphtoquinone-1, 4

The naphthoquinone that were chosen for this study are:

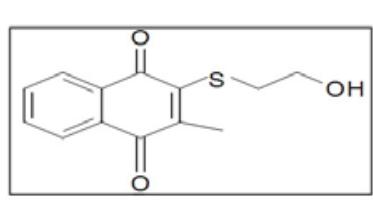

Inhibitor_1 (Cpd5)

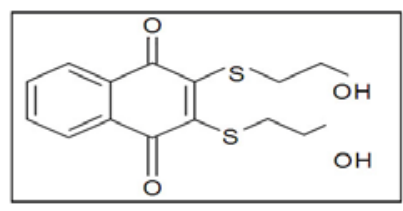

Inhibitor_2 (NSC95397)
The downloading of Cdc25 phosphatase was made from a database Bookhaven Protein Data Bank (access code 1QB0). The three dimensional structure of the
Cdc25 phosphatase was obtained by X-ray diffraction with a resolution $(1.91 \AA)$ [4]. We note that the phosphatase Cdc25 crystallizes as a monomer (Figure 2) with 178 residues and 1480 atoms. The three- dimensional structure of Cdc25 phosphatase was obtained by diffraction in x-ray with a resolution (1.91 A) [35]. It is noticed that Cdc25 phosphatase crystallizes in the shape of a monomer (Figure 3) with 178 residues and 1480 atoms.

The downloading of Cdc25 phosphatase was made from a database Bookhaven Protein Data Bank (access code 1QB0). The three dimensional structure of the Cdc25 phosphatase was obtained by X-ray diffraction with a resolution $(1.91 \AA)$ [4]. We note that the phosphatase Cdc25 crystallizes as a monomer (Figure 2) with 178 residues and 1480 atoms. The three- dimensional structure of Cdc25 phosphatase was obtained by diffraction in x-ray with a resolution (1.91 $\AA$ ) [36]. It is noticed that Cdc25 phosphatase crystallizes in the shape of a monomer (Figure 3) with 178 residues and 1480 atoms.

With the reducing effect of molecular modeling, we simplified the model of the enzyme by removing water molecules, this has enabled us to obtain the model given in (Figure 4). This model includes amino acids forming the active site (Figure 5).

\section{Optimization of Cdc25 Phosphatase}

The geometry optimization of the Cdc25 phosphatase was performed using the force field Amber99 [4] implemented in the software Hyperchem7.5 professional version. The main chain was kept rigid, whereas the side chains are flexible. This approximation allows the side chains of proteins more easily find the position in which interactions are most favorable. The value of the energy optimization is:

$$
\mathrm{E} \mathrm{Opt}=-8500.78 \mathrm{Kcal} / \mathrm{mol}
$$

\section{Optimization of the Inhibitors}

The construction and the optimization of ligand were made by program EMO (Energy of Molecule). The results obtained are shown in the following Table 1:

Table 1. Results obtained using program EMO.

\begin{tabular}{|c|c|c|c|c|c|c|}
\hline Energy steric (KJ/mol) & $\mathbf{E}_{\text {Stretchi ng }}$ & $\mathbf{E}_{\text {Bending }}$ & $\mathbf{E}_{\text {To rsion }}$ & $E_{V d w}$ & $\mathrm{E}_{\text {Electrost atic }}$ & $\mathbf{E}_{\text {Steric }}$ \\
\hline
\end{tabular}




\begin{tabular}{lllllll}
\hline Inhibitor_2(NSC95397 & 03.35 & 28.01 & 07.06 & 60.68 & 00.00 & 99.09 \\
\hline
\end{tabular}

\section{Molecular Dynamics of Cdc25 Phosphatase}

We began dynamics with an initialization of the system: with $\mathrm{t}=0$ we have $\mathrm{R}(\mathrm{T})=0$, i.e. the initial structure, previously minimized. Then we heated the system up to $300 \mathrm{~K}$ during 1000 steps with an integration step of $1 \mathrm{fs}$. In $300 \mathrm{~K}$, there is a balance: the speeds are adjusted to keep the temperature constant (there is exchange between the kinetic energy and the potential energy). Then, there is production of conformations. The time of simulation of the molecular dynamics is 100 picoseconds.

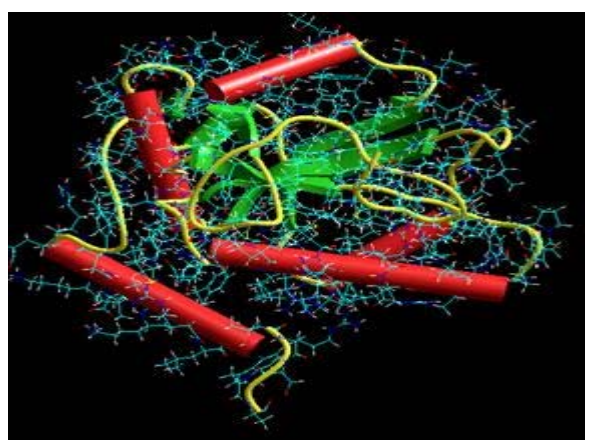

1QB0: Code of PDB Bank

\section{Molecular Dynamics of the Inhibitors}

\subsection{Inhibitor_1(Cpd 5)}

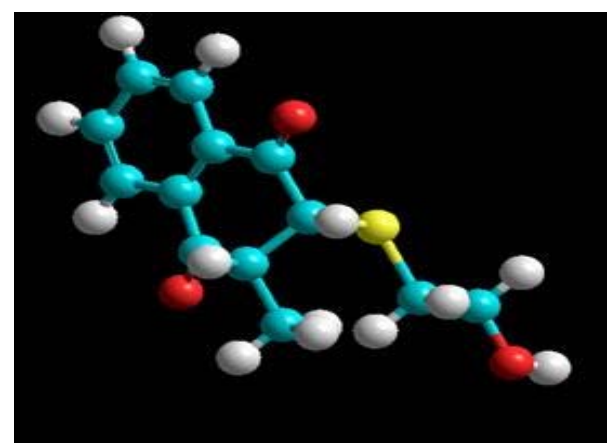

5.2. Inhibitor_2(NSC 95397)

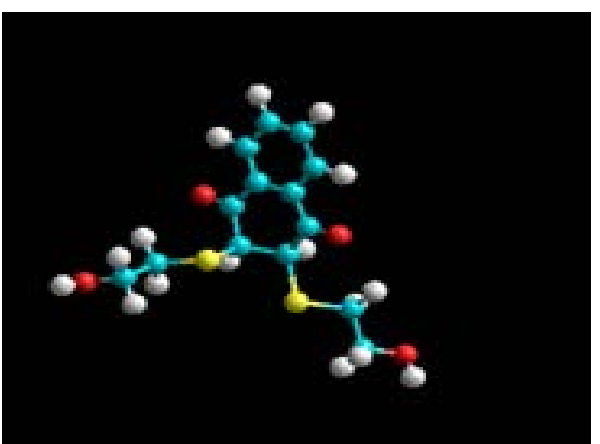

\section{Docking of the Substrates and Construction of the Complexes}

The next stage, after the construction of the ligands, is the positioning of these molecules in the active site of Cdc25 phosphatase.To do this, we used molecular docking module of the software Hex4 [1] Once all the complexes formed, we will perform a geometry optimization and molecular dynamics calculations to find the most stable conformation.

\subsection{Complex 1QB0 Inhibitor_1 (Cpd 5)}

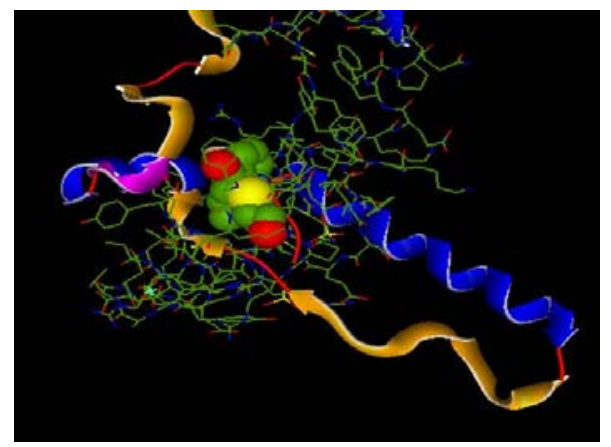

\subsection{Complex 1QB0 Inhibitor_2 (NSC 95397)}

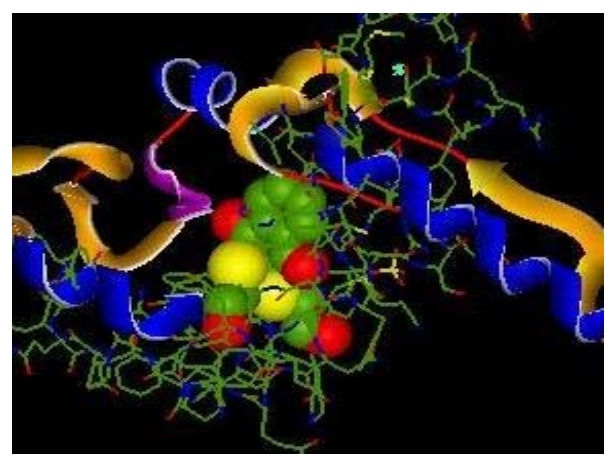

7. Distances Between the Amino Acids of the Active site and Groups of Inhibitors 


\subsection{Inhibitor1 (Cpd 5) Table 2}

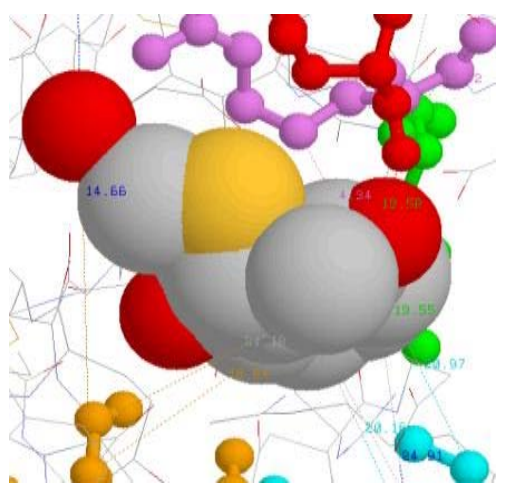

Table 2. Measured distances between the inhibitor_1 (Cpd 5) and groups of side chains of amino acids responsible for interaction.

\begin{tabular}{cccccc}
\hline $\begin{array}{c}\text { Distances } \\
\left(\mathbf{A}^{\mathbf{0}}\right)\end{array}$ & Arg544 & Arg482 & Arg479 & Ser477 & Glu474 \\
\hline $\begin{array}{c}\text { Inhibitor_1 } \\
\text { (Cpd 5) }\end{array}$ & 20.17 & 18.09 & 12.26 & 13.08 & 14.10 \\
\hline
\end{tabular}

\subsection{Inhibitor_2 (NSC 95397) Table 3}

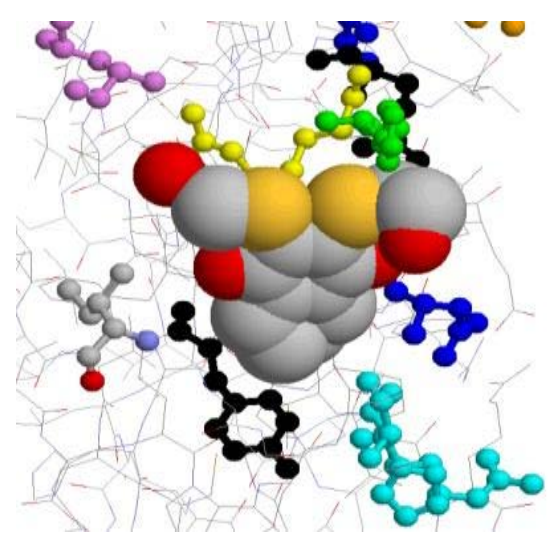

In order to establish correlations between interaction energies and activities, and to consider what kind of forces by the nature of interactions phosphatase Cdc25substrate is governed, we often refer to a decomposition of the total potential energy of the molecule into several terms (electrostatic energy, Energy VDW, ...). The interaction energies between the different substrates studied and the phosphatase Cdc25 are evaluated using the following equation:

E (interaction) $=[E$ pot (Complex Enzyme- Inhibitor) $]$ - [E pot (Enzyme) +E pot (Inhibitor)]

We must also take into account interactions of Van Der Waals since it is the interactions between atoms that stabilize non-enzyme-inhibitor complexes. Table 4.

\section{Discussion}

In light of the results, it appears that the introduction of bulky groups causes a conformational rearrangement within the active site pocket, which probably will increase the complementarity and consequently the activity.

Table 3. Measured distances between the inhibitor_2 (NSC 95397) and the groups of side chains of amino acids responsible for interaction.

\begin{tabular}{lccccc}
\hline $\begin{array}{l}\text { Distances } \\
\text { (A0) }\end{array}$ & Arg544 & Arg482 & Arg479 & Ser477 & Glu474 \\
\hline $\begin{array}{l}\text { Inhibitor_2 } \\
\text { (NSC95397) }\end{array}$ & 4.90 & 3.19 & 3.82 & 3.34 & 5.48 \\
\hline
\end{tabular}

Table 4. Balance of energies ( $\mathrm{kcal} / \mathrm{mol})$.

\begin{tabular}{ccccccc}
\hline Inhibitors & 1 & 2 & 3 & 4 & 5 & 6 \\
\hline In_1 Cpd 5 & 420.96 & 19.8 & -549.13 & 12.4 & -224.22 & 6490.80 \\
In_2 NSC & 3020.92 & 25.93 & -561.35 & 13.76 & -578.3 & 1434.17
\end{tabular}

1. Etotal. pot of the complex E-I (Kcal/mol); 2. Etotal. Pot of the inhibitor I (Kcal/mol); 3. Evdw (complex-inhibitor) (Kcal/mol); 4. EVdw (inhibitor) (Kcal/mol); 5. Einter. de Vdw (Kcal/mol); 6. E inter. totale (Kcal/mol). Energy VDW phosphatase Cdc25 alone $=-337,399 \mathrm{kcal} / \mathrm{mol}$; Energy steric phosphatase Cdc25 alone $=-6089,399 \mathrm{kcal} / \mathrm{mol}$. Table 5 .

Table 5. Review of molar volumes (Å3).

\begin{tabular}{lc}
\hline & Molar volume Å3 \\
\hline Inhibitor_1 & 1231.53 \\
Inhibitor_2 & 980.28 \\
\hline
\end{tabular}

We measured the distances between the $\mathrm{R}$ groups of naphthoquinones, and those side chains of amino acids making up the active site and possibly other groups the main chain of the enzyme responsible for interaction (which may cause a conformation favorable to a high complementarity resulting in consistent activity). The measured distances vary etween $3.19 \AA$ and $20.17 \AA$ for all complexes studied. The interactions between $2.5 \AA$ and $3.5 \AA$ are considered high and those between $3.1 \AA$ and $3.55 \AA$ are assumed averages. Interactions greater than $3.55 \AA$ are weak or absent [5].

Based on the total interaction energy, we note that the inhibitor_2 (NSC 9537) (1434.17 kcal/mol) is more active than inhibitor_1 (Cpd 5) (6490.80 kcal/mol).

For the interaction energy of Van Der Waals (generally used to explain the interactions between atoms not bound to stabilize the enzyme-inhibitor complex), we notice that the inhibitor 2 (NSC95397) (578 $317 \mathrm{kcal} /$ $\mathrm{mol}$ ) is more stable than inhibitor 1(Cpd 5) (224228 $\mathrm{Kcal} / \mathrm{mol})$. Molar volumes show that the inhibitor 2 (NSC 95397) (980.28 $\AA 3$ ) have a geometry lower than inhibitor 1(Cpd 5) (1231.53 Å3). 
From these results we can conclude that complementarty is relatively important for the inhibitor_2 (NSC 95397).

Note that we can discuss complementarity in increasing or decreasing the interval size of the active site pocket, in our case with a geometry of $8.47 \AA$ depth, opening $14.86 \AA 10.22 \AA$, this pocket is narrowed up to a width of $13.8 \AA$.

Taking into account different geometrical constraints, the approach considered inhibitors can influence the complementarity and thereafter the activity (Table 6).

The distance between the $\mathrm{O}$ and the $\mathrm{O}$ is $6.53 \AA$ for the ligand atom. Inside the cavity of active site this distance increase the $9.99 \AA$.

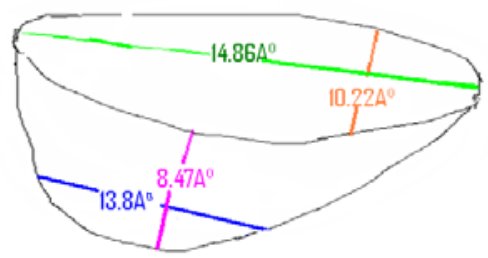

Dimensions of the enzyme

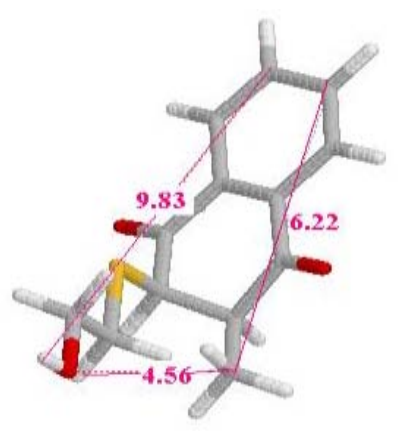

Inhibitor_1 (Cpd 5)

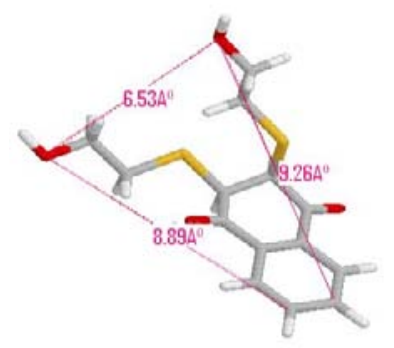

inhibitor_2 (NSC 95397)

Table 6. Distances between the atom.

\begin{tabular}{lccccc}
\hline \multicolumn{1}{c}{ Distances ( $\mathrm{A})$} & $\begin{array}{c}\mathrm{d} \\
(\mathrm{C}-\mathrm{S})\end{array}$ & $\begin{array}{c}\mathrm{d} \\
(\mathrm{C}-\mathrm{O})\end{array}$ & $\begin{array}{c}\mathrm{d} \\
(\mathrm{O}-\mathrm{S})\end{array}$ & $\begin{array}{c}\mathrm{d} \\
(\mathrm{O}-\mathrm{O})\end{array}$ & $\begin{array}{c}\mathrm{d} \\
(\mathrm{S}-\mathrm{S})\end{array}$ \\
\hline $\begin{array}{l}\text { Inhibitor1 (cpd5) } \\
\text { In cavity }\end{array}$ & 3.07 & 5.76 & 3.37 & & \\
$\begin{array}{l}\text { Inhibitor2 } \\
\text { (NSC95397) }\end{array}$ & 5.06 & 8.71 & 3.20 & 9.99 & 3.30 \\
\begin{tabular}{l} 
In cavity \\
\hline
\end{tabular} & & & & & \\
\hline
\end{tabular}

\begin{tabular}{lccccc}
\hline $\begin{array}{l}\text { Only inhibit- } \\
\text { tor1 (cpd5) }\end{array}$ & 2.93 & 4.56 & 3.18 & & \\
$\begin{array}{l}\text { Only inhibit- } \\
\text { tor2(NSC95397) }\end{array}$ & 3.56 & 5.39 & 3.13 & 6.53 & 3.42 \\
\hline
\end{tabular}

\section{Conclusions}

We are observed phenomena of interaction of the substrate and the atoms of residues in the active site. The atoms of substrate and residues interreges together and we are characterized the lengths of bond are abnormally i.e. very long and the angles are very different of normal structure of these compounds. It is difficult to extract this molecule from this cavity and consequently there are very stable complexes.

To conclude, in view of the results obtained in this work which involves the elucidation of the inhibition of the phosphatase Cdc25 by the methods of molecular modeling, it is clear that the inhibitor 2 (NSC 95397) has probably a better inhibition of Cdc25 phosphatase. According to the calculated energies, distances and volume we note that the inhibitor 2 (NSC 95397) is more stable with the most basic energy, distances smaller and less bulky.

\section{References}

[1] K. Saad, C. Jasmin, "Substances naturelles végétales cytotoxiques et antitumorales," Cancer Hachette, 1979.

[2] J. L. Amiel, Abrégé de Cancérologie Tome TI Ed Masson, 1984, 292 p.

[3] M. Daunf, R. P. P. FllchsLa, “cancérogenèse chimique,” La recherche sur le cancer Ed Seuil Pts Sciences, 1982, pp. 27-43.

[4] J. Kermarec, “Anatomie pathologie générale la signification biologique des lésions Tome II,” Ed. Vigot/CEF Nice, 1985, pp. 551-554.

[5] A. Tchakline, "Le cancer problème du siècle,” Moscou Ed MIR, 1980, 195 p.

[6] C. Quenum, R. Camatn, R. Bayelet, "Le cancer en Afrique noire épidémiologie et pathologie géographique du cancer en Afrique,” Médecine d'AL Noire, Vol. 1, No. 3, 1971, pp. 165-185.

[7] V. Azais, Vitamine A EMC (Paris-France) Endocrinologie-Nutrition The (2) 25-2ü2-F-2ü, 1995, 5 p.

[8] J. Tredaniel, J. M. Extra, E. Lepage, P. Brice, Actualités thérapeutiques en cancérologie EMC THE (2), 25140-A ${ }^{10}$.

[9] 8 Desoize, F. Marechal, "Principes de la chimiothérapie anticancéreuse,” Le moniteur internat, n’23, pp. 47-56.

[10] P. Poutllart, T. Palangie, M. Jouve, E. Garcia-Giralt, B. Bretalldealj, “Approche thérapeutique des cancers," EM.C (Paris- France), Thérapeutique (2), 6 - 1984, $25140 \mathrm{~A}^{10}, 36 \mathrm{p}$. 
[11] I. Nilsson, I. Hoffman, "Cell Cycle Regulation by the cdc25 Phosphatase Family,” Progress in Cell Cycle Research, Vol. 4, 2000, pp. 107-114.

[12] K. Kristjánsdóttir and J. Rudolph, "Cdc25 Phosphatases and Cancer,” Chemistry and Biology, Vol. 11, No. 8, 2004, pp. 1043-1051. doi:10.1016/j.chembiol.2004.07.007

[13] K. E. Pestell, A. P. Ducruet, P. Wipf and J. S. Lazo, "Synthèse totale d'un inhibiteur de phosphatases TMC-69-6H,” Oncogene, 2000, Vol. 19, pp. 6607-6612. doi:10.1038/sj.onc.1204084

[14] J. Rudolph, "Cdc25 Phosphatases: Structure, Specificity, and Mechanism,” Biochemistry, Vol. 46, No. 12, 2007, pp. 3595-3604. doi:10.1021/bi700026j

[15] D. Bardford, A. J. Flint and N. K. Tonks, "Crystal Structure of Human Protein Tyrosine Phosphatase 1B,” Science, Vol. 263, No. 5152, 1994, pp. 1397-1404. doi:10.1126/science.8128219

[16] S. Herna'ndez, X. Bessa, S. Bea', L. Herna'ndez, A. Nadal, C. Mallofre', J. Muntane, A. Castells, P. L. Ferna'ndez, A. Cardesa and E. Campo, "Differential Expression of Cdc25 Cell-Cycle-Activating Phosphatases in Human Colorectal Carcinoma,” Laboratory Investigation, Vol. 81, 2001, pp. 465-473.

[17] I. Takemara, H. Yamamoto, M. Sekimoto, M. Ohue, S. Noura, Y. Miyake, T. Matsumoto, T. Aihara, N. Tomita, Y. Tamaki, I. Sakita, N. Kikkawa, N. Matsuura, H. Shiozaki and M. Monden, "Overexpression of Cdc25B Phosphatase as a Novel Marker of Poor Prognosis of Human Colorectal Carcinoma,” Cancer Research, Vol. 60, 2000, pp. 3043-3050.

[18] E. S. W. Ngan, Y. Hashimoto, X.-Q. Ma, M. J. Tsai and S. Y. Tsai, "Overexpression of Cdc25B, an Androgen Receptor Coactivator, in Prostate Cancer,” Oncogene, Vol. 22, 2003, pp. 734-739. doi:10.1038/sj.onc.1206121

[19] W. G. Wu, Y. H. Fan, B. L. Kemp, G. Walsh and L. Mao, "Overexpression of Cdc25A and cdc25B Is Frequent in Primary Nonsmall Cell Lung Cancer But Is Not Associated with Overexpression of C-myc," Cancer Research, Vol. 58, No. 18, 1998, pp. 4082-4085.

[20] H. Sasaki, H. Yukiue, Y. Kobayashi, M. Tanahashi, S. Moriyama, Y. Nakashima, I. Fukai, M. Kiriyama, Y. Yamakawa and Y. Fujii, "Expression of the Cdc25B Gene as a Prognosis Marker in Non-Small Cell Lung Cancer,” Cancer Letters, Vol. 173, No. 2, 2001, pp. 187192. doi:10.1016/S0304-3835(01)00669-3

[21] K. Kristjansdottir and J. Rudolph, "Cdc25 Phosphatases and Cancer,” Chemistry \& Biology, Vol. 11, No. 8, 2004, pp. 1043-1051. doi:10.1016/j.chembiol.2004.07.007

[22] K. Galaktionov, A. K. Lee, J. Eckstein, G. Draetta, J. Meckler, M. Loda and D. Beach, "Cdc25 Phosphatases as Potential Human Oncogenes,” Science, Vol. 269, No. 5230, 1995, pp. 1575-1577. doi:10.1126/science.7667636
[23] A. Fernandez-Vidal, L. Ysebaert, C. Didier, R. Betous, F. D. Toni, N. Prade-Houdellier, C. Demur, M.-O. Contour-Galce'ra, G. P. Prévost, B. Ducommun, B. Payrastre, C. Racaud-Sultan and S. Manenti, "Cell Adhesion Regulates Cdc25A Expression and Proliferation in Acute Myeloid Leukemia,” Cancer Research, Vol. 66, No. 14, 2006, 7128-7135. doi:10.1158/0008-5472.CAN-05-2552

pp.

[24] Y. Nishikawa, B. I. Carr, M. Wang, S. Kar, F. Finn, B. Dowd, Z. B. Zheng, J. Kerns and S. Naganathan, " Growth Inhibition of Hepatoma Cells Induced by Vitamin K and Its Analogs,” Journal of Biological Chemistry, Vol. 270, No. 47, 1995, pp. 28304-28310. doi:10.1074/jbc.270.47.28304

[25] R. Boutros, C. Dozier and B. Ducommun, "The When and Wheres of Cdc25 Phosphatases," Current Opinion in Cell Biology, Vol. 18, No. 2, 2006, pp. 185-191. doi:10.1016/j.ceb.2006.02.003

[26] E. B. Fauman, J. P. Cogswell, B. Lovejoy, W. J. Rocque, W. Holmes, V. G. Montana, H. Piwnica-Worms, M. J. Rink and M. A. Saper, "Crystal Structure of the Catalytic Domain of the Human Cell Cycle Control Phosphatase, Cdc25A,” Cell, Vol. 93, No. 4, 1998, pp. 617-625. doi:10.1016/S0092-8674(00)81190-3

[27] R. A. Reynolds, A. W. Yem, C. L. Wolfe, M. R. Deibel, C. G. Chidester and K. D. Watenpaugh, "Crystal Structure of the Catalytic Subunit of Cdc25B Required for G2/M Phase Transition of the Cell Cycle," Journal of Molecular Biology, Vol. 293, No. 3, 1999, pp. 559-568. doi:10.1006/jmbi.1999.3168

[28] M.-O. Contour-Galce'ra, A. Sidhu, G. Prév vost, D. Bigg and B. Ducommun, "What's New on Cdc25 Phosphatase Inhibitors,” Pharmacology \& Therapeutics, Vol. 115, No. 1, 2007, pp. 1-12. doi:10.1016/j.pharmthera.2007.03.009

[29] G. P. Prevost, M.-C. Brezak, F. Goubin, O. Mondesert, M.-O. Galcera, M. Quaranta, F. Alby, O. Lavergne and B. Ducommun, "Inhibitors of theCdc25 Phosphatases," Progress in Cell Cycle Research, Vol. 5, 2003, pp. 225-234.

[30] J. Rudolph, “Inhibiting Transient Protein-Protein Interactions: Lessons from the Cdc25 Protein Tyrosine Phosphatases," Nature Reviews Cancer, Vol. 7, No. 3, 2007, pp. 202-211.

[31] R. Boutros, V. Lobjois and B. Ducommun, "CDC25 Phosphatases in Cancer Cells: Key Players? Good Targets?” Nature Reviews Cancer, Vol. 7, No. 8, 2007, pp. 495-507. doi:10.1038/nrc2169

[32] S. Cao, C. Foster, M. Brisson, J. S. Lazo, D. G. Kingston, I. Bioorg, "Evaluation biologique de l'inhibition desphosphatases cdc25 dans des lignées d'adénocarcinomes mammaires humains," Journal of Medicinal Chemistry, Vol. 13, No. 4, 2005, pp. 999-1003

[33] S. P. Gunasekera, P. J. McCarty and M. Kelly-Borges, "Studies in Natural Products Chemistry: Bioactive Natural Products," Journal of the American Chemical Society, Vol. 118, No. 36, 1996, pp. 8759-8760. doi:10.1021/ja961961+ 
[34] R. E. Cebula, J. L. Blanchard, M. D. Boisclair, K. Pal and N. J. Bockovich, Bioorganic \& Medicinal Chemistry Letters, Vol. 7, No. 15, 1997, pp. 2015-2020. doi:10.1016/S0960-894X(97)00357-0

[35] D. R. John and C. C. Marjorie, "Chimie Organique Moderne,” Merck Index, 11th Edition, 1975, p. 651.
[36] R. G. Ewan, Y. Xiong, J. Melanie, L. D’andrea and Lynne Regan, "Design of Stable $\alpha$-Helical Arrays from an Idealized TPR Motif,” Elsevier Science Ltd., Vol. 11, 2003, pp. 497-508. 